\title{
Re-expansion pulmonary edema following treatment of spontaneous pneumothorax during oral surgery
}

\author{
Yoshihiro Momota, DDS · Teruyuki Yasutome, DDS • \\ Junichiro Kotani, DDS · Naoki Higashibeppu, MD • \\ Nobuoki Tomemori, MD
}

Received: 5 March 2009/ Accepted: 7 May 2009/Published online: 22 May 2009

(c) Canadian Anesthesiologists' Society 2009

\section{To the Editor,}

Re-expansion pulmonary edema (REPE) often develops as edema with increased permeability and warning signs including dyspnea, cough, bloody foam-like sputum developing within $2 \mathrm{hr}$ after rapid re-inflation of the lung, and subacute ( $\geq 3$ days) or chronic collapse. ${ }^{1,2}$ A 58-yr-old male with mandibular gingival cancer and a history of transient pleuritic pain three days prior to surgical resection of the cancer underwent general anesthesia. Preoperative spirography revealed restrictive impairment, and a plain chest $x$-ray revealed no evidence of bullae, although clear lung markings were not visible at the apex of the right lung. After nasotracheal intubation, breath sounds decreased in the patient's right lower lung and insufficient movement of his right chest was observed. During surgery, the patient's lungs were ventilated using intermittent positive pressure ventilation (IPPV). Lung collapse occurred after surgery had been in progress for about $4.5 \mathrm{hr}$. A chest $x$-ray revealed collapse of all portions of the right lung and left mediastinal shift (Fig. 1). The lung collapse was treated with tube drainage to evacuate $1000 \mathrm{~mL}$ of air over $15 \mathrm{~min}$. Immediately after drainage was initiated, frothy secretions were observed in the endotracheal tube. Chest $x$-ray examination at that time revealed diffuse infiltration of the right lung, and pulmonary edema developed immediately after re-expansion of the collapsed alveoli (Fig. 1). The patient was treated with dexamethasone, albumin, diuretics, and frequent suction, but

Y. Momota, DDS ( $₫) \cdot$ T. Yasutome, DDS · J. Kotani, DDS

Osaka Dental University, Osaka, Japan

e-mail: momoda@cc.osaka-dent.ac.jp

N. Higashibeppu, MD · N. Tomemori, MD

Osaka Red Cross Hospital, Osaka, Japan he continued to exhibit hypoxemia and dyspnea. Positive end-expiratory pressure ventilation (PEEP) and aggressive tracheal suctioning were initiated, and the patient's condition improved over a 60 -hr period.

A follow-up interview with our patient after recovery revealed that he had experienced sudden back pain when descending stairs three days before surgery, but he ignored the warning signs because the pain disappeared within a few minutes. It is very likely that a small spontaneous pneumothorax developed at that time. If chest $x$-ray examination had been performed when the abnormal respiratory sounds occurred, pneumothorax may have been detected earlier and development of REPE may have been prevented. The mechanisms of developing REPE are believed to include a direct consequence of low alveolar oxygen concentration associated with long-lasting lung collapse and an increase in the permeability of pulmonary blood vessels by vasoactive substances due to an acute increase in blood flow in pulmonary capillary vessels. ${ }^{3}$ In the present case, lungs with long-term collapse were treated with controlled positivepressure ventilation $\left(\mathrm{F}_{\mathrm{I}} \mathrm{O}_{2}=43 \%\right)$. Although $\mathrm{PaO}_{2}$ was maintained at $\geq 100 \mathrm{mmHg}$ during surgery, permeability of lung vessels was increased after re-inflation. Abrupt increase in blood flow in pulmonary capillaries rather than hypoxemia in the alveoli was considered a principal cause of the development of REPE. Due to spontaneous pneumothorax, slow re-inflation using a Heimlich valve or water seal device is recommended when treating patients with chronic lung collapse. ${ }^{4}$ In our case, the rapid evacuation over about 15 min using a chest tube appeared to have increased blood flow in the pulmonary capillary vessels and promoted the development of REPE. REPE is usually treated with artificial ventilation using oxygen therapy or PEEP, corticosteroids, and diuretics. ${ }^{5}$ In our patient, respiratory management using synchronized intermittent mandatory ventilation and PEEP 

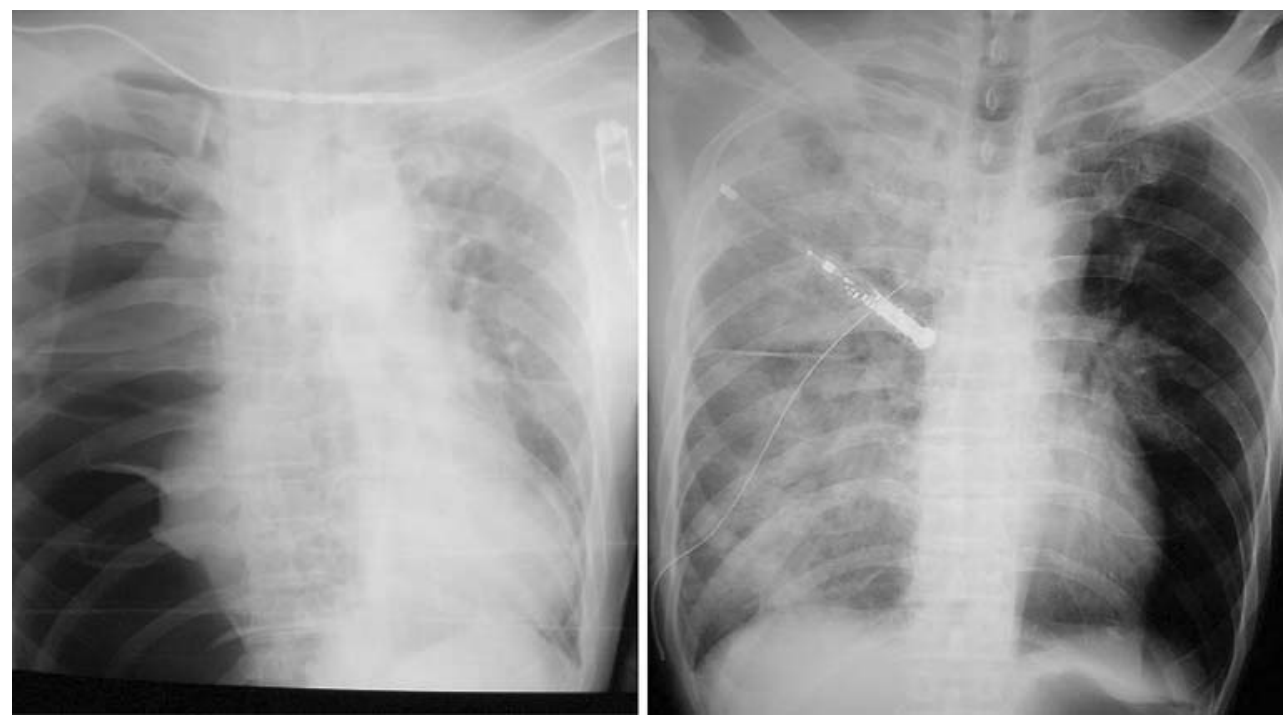

Fig. 1 Diagnosed pneumothorax of the right lung (upper) and unilateral re-expansion pulmonary edema (lower) at the chest $x$-ray

was beneficial in decreasing airway secretions within a relatively short period of time. Although no consensus exists regarding the optimal level of PEEP for patients with REPE, we were able to treat our patient with $10 \mathrm{~cm} \mathrm{H}_{2} \mathrm{O}$, a standard level of PEEP.

It is important to carefully evaluate the length of time and severity of lung collapse and avoid rapid de-airing with excessive negative pressure when patients with pneumothorax are treated with chest tube drainage. Considering the risk of REPE when air evacuation is performed for the treatment of lung collapse, the speed and volume of de-airing should be carefully controlled. We obtained patient consent for publication of personal information.

Acknowledgments The author thanks Dr. Alan A. Artru, Professor of Anesthesiology at the University of Washington, School of Medicine, Seattle, Washington for reviewing this case report and for his valuable comments and suggestions.
Conflicts of interest None declared.

\section{References}

1. Waqaruddin M, Bernstein A. Re-expansion pulmonary oedema. Thorax 1975; 30: 54-60.

2. Carlson RI, Classen KL, Gollan F, Gobbel WG Jr, Sherman DE, Christensen RO. Pulmonary edema following the rapid reexpansion of a totally collapsed lung due to a pneumothorax: a clinical and experimental study. Surg Forum 1958; 9: 367-71.

3. Said SI. Endocrine role of the lung in disease. Am J Med 1974; 57 : 453-65.

4. Tarver RD, Broderick LS, Conces DJ Jr. Reexpansion pulmonary edema. J Thorac Imaging 1996; 11: 198-209.

5. Mahfood S, Hix WR, Aaron BL, Blaes $P$, Watson DC. Reexpansion pulmonary edema. Ann Thorac Surg 1988; 45: 340-5. 